\title{
EDUCACIÓN
}

\section{Opinión de la Comunidad Educativa del CEMA (Complejo Educativo María Auxiliadora) sobre el programa Pastoral Educativo, años 2013 - 2015}

\author{
Elvira Peralta de Quiñónez'
}

\begin{abstract}
Resumen
Introducción: En el contexto internacional existe una marcada preocupación respecto a los mecanismos de la calidad en la educación, ello impulsado en los procesos de transformación de la educación en general, el crecimiento de la oferta y demanda, la globalización, las exigencias del mundo laboral impulsan a que "una educación sometida a profundas revisiones, se reflexiona acerca de la práctica educativa y se realizan reformas en todos los niveles de enseñanza". La presente investigación responde al interés de profundizar dos de los cuatro pilares de la Educación propuestos por la UNESCO (1998) el "Aprender a ser" y "Aprender a Convivir", plasmados en el Proyecto Educativo Institucional (PEI) del CEMA, que desde el año 2011 ha incorporado en el mismo el componente espiritual, situación que requiere ser analizada de manera objetiva.
\end{abstract}

Objetivo: Describir la opinión de la Comunidad Educativa del Complejo Educativo María Auxiliadora sobre el Programa Pastoral Educativo en los años 2013- 2015

Material y Método: Metodología "Descriptivo Referencial", sustentado en estudios documentales; con un Diseño "No Experimental" pues no hubo manipulación de variables, un "Enfoque "Cualitativo", pues sólo ha utilizado técnicas cualitativas de recogidas de datos.

Resultados: Los Valores en el Contexto Educativo Paraguayo: En el Paraguay, la educación en valores es entendida, como uno de los ejes fundamentales para trabajar el "ser" del estudiante. Este tema lo trabaja en Educación Escolar Básica en el Componente Fundamental: Democracia, Familia y Ambiente y en Educación Media, en las Transversales, que son denominados así, pues permean implícitamente en todo el Currículum Educativo Nacional

Los principios fundamentales que sustenta el Programa Pastoral del CEMA giran en torno a ejes fundadas en la Propuesta Preventiva de Don Bosco, que apunta a una relación Dinámica y Vivencial y son la búsqueda y promoción de los valores, el fortalecimiento armónico de las relaciones y esquemas de valores

\footnotetext{
1. Universidad María Auxiliadora. Facultad de Ciencias y Humanidades.

Es una Tesis presentada para la obtención del Título de Magíster en Educación, en la Universidad María Auxiliadora.
}

E-mail: eperalta@umax.com

DOI: 10.26885/rcei.foro.2018.48 


\section{Opinión del CEMA sobre el programa Pastoral Educativo. Peralta de Quiñónez}

y la toma de decisiones de los alumnos.

Fortalezas encontradas: Para los alumnos el Programa es muy importante pues los acerca a Dios, los ayuda mucho en su vida personal y cumple con las expectativas y a concienciarlos. Y para los docentes, el Programa ayuda a mejorar el relacionamiento con los niños y el ambiente escolar. Destacaron que vivencias cambios significativos en las conductas de los alumnos y hay mejor relacionamiento con las familias.

Debilidades encontradas: para los alumnos falta cantar más músicas sobre Dios, respetar a las personas que son de otra religión, y falta mejor organización de las misas y en los sermones, también que los docentes hablen más de Dios. Para los docentes falta mejorar los materiales para usar con los alumnos y dinamizar las clases de religión. Los padres, por su parte, mencionaron que la debilidad es el control, la corrección y calificación de los cuadernillos de sus hijos, la falta de incentivación a los jóvenes, la falta de difusión del Programa Pastoral y en la enseñanza de religión.

Conclusiones: La propuesta de Complejo Educativo María auxiliadora en el Programa Pastoral, se encuentra inserta en la Educación en Valores y plantea una propuesta que busca un acercamiento a los diferentes estamentos de la comunidad educativa y de construcción de la Promoción de los Valores de la religión católica, a partir de la propuesta planteada por Don Bosco. Este Programa es bien vista por toda la comunidad educativa, considerando que todos coinciden en que ayuda al cambio de actitud de los alumnos, a la mejora del clima escolar, sienten la necesidad de abarcar más horas, mejorar la calidad de los sermones y de materiales didácticos, así como de enfocarse más en el control de los cuadernillos.

Palabras clave: programa pastoral, educación en valores, comunidad educativa.

\section{Referencias}

Coombs, H. (2005). La crisis mundial de la educación. Perspectivas actuales. Madrid: Santillana.

González Pcheco, O. (1994). Currículo, diseño, práctica y evaluación. Centro de Estudios en el Perfeccionamientos de Educación Superior. La Habana: Universidad de La Habana.

Ministerio de Educación y Ciencias. (1998). Haciendo currículo contextualizado$3^{\circ}$ Ciclo. Asunción: MEC.

Morán, E. (1999). Los siete saberes necesarios para la educación del futuro. Buenos Aires: Nueva Visión.

UNESCO (1998). La educación encierra un tesoro. Paris: Cumbre internacional. 